children and ail females from the count. With an increasing interest in sport generally, and a number of social changes, which, in the last $5^{\circ}$ years, have eased the position of lower income groups and altered the attitude of women to athletics, the number of people able to indulge a taste for athletics is increasing considerably, perhaps to as much as 2 or 3 million, and such an increase may well be critical, since a really firstclass athlete is a rare phenomenon, turning up perhaps once in a million or so. If this view is correct, it means we may expect to see records broken over a few years yet, but with diminishing frequency until, for each nation, a set of figures is reached, representing-though not in a way of much scientific interest, since science is more concerned with averages than with extremes-the abilities of that nation in the field of athletics. Subsequently, even this set of figures might be expected to show slow improvement, but in this connexion, we should take warning from the observation made by A. V. Hill in 1927 , that the speeds of race-horses, which have been officially recorded for nearly two centuries in this country, have not improved at all in this interval despite the fact that it represents the results of forty or fifty generations of selective breeding (using as much money, incidentally, as might have founded and maintained several excellent institutes of genetics). Where the human population is concerned, with a complete absence of selective breeding, changes in intrinsic athletic ability in any calculable number of generations are out of the question, and the only improvement which it is reasonable to expect would be an improvement attributable to improved nutrition-for which there is plenty of scope.

On the second question, whether British athletic prowess has fallen off because of dietary restrictions, I have no opinion to offer. It would, indeed, be presumptuous of me in such a gathering, but I think we should remember that the war had other effects upon our youth than that upon diet. Much time that might otherwise have been devoted to athletics was spent in a different kind of training; the playing fields of Eton had indeed remarkably little to do with the winning of this war, but perhaps in a few years of peace they may produce once again a crop of first-class athletes.

\title{
REFERENCES
}

Bloch, K. \& Schoenheimer, R. (1940). F. biol. Chem. 134, 785.

Clark, A. J., Eggleton, M. G. \& Eggleton, P. (1932). F. Physiol. 75, 332.

Gardiner, E. N. (1910). Greek Athletics, Sports and Festivals. London: Macmillan.

Margaria, R., Edwards, H. T. \& Dill, D. B. (1933). Amer. F. Physiol. 106, 689.

Pantin, C. F. A. (1930). Proc. roy. Soc. B, 105, 538.

Vigneau, V. du, Chandler, J. P., Cohn, M. \& Brown, G. B. (1940). F. biol. Chem. 134, 787.

\section{Chemical Aspects of Muscular Contraction}

\section{By Dorothy M. NeEdham, Biochemical Laboratory, University of Cambridge}

In the biochemistry of muscle contraction, two lines of work, followed independently for some 50 years and only recently coming together, must be considered. One is the nature of the muscle machine, the other the nature of the essential fuel. 


\section{The nature of the essential fuel}

Since, in anaerobic contraction, lactic acid formation was for 20 years the only energy-yielding reaction known to occur and since this formation went on in amounts proportional to the tension developed, it was naturally regarded as closely associated with contraction (Fletcher \& Hopkins, 1917; Meyerhof, 1930). The discovery of the alkaline contraction in iodoacetate-poisoned muscles (where creatine phosphate (CP) breakdown goes on and is proportional to the tension) led to the suggestion that this dephosphorylation (Lundsgaard, 1930) is a source of energy nearer to the contractile machine; and many facts accumulated showing that CP breakdown does indeed precede carbohydrate breakdown in the contracting muscle $\mathrm{pH}$ changes, direct estimation of the ratio of $\mathrm{CP}$ breakdown to carbohydrate breakdown at successive stages in a series of contractions, volume changes, transparency changes; see Needham, 1937).

Then came the evidence from Lohmann (1934) that, in muscle extract, CP is not hydrolysed directly, but only through interaction with adenylic compounds and intervention of adenosine triphosphatase (ATPase):

$$
\mathrm{CP}+\mathrm{ADP} \rightarrow \mathrm{C}+\mathrm{ATP}, \quad \mathrm{ATP} \rightarrow \mathrm{ADP}+\mathrm{H}_{3} \mathrm{PO}_{4}
$$

(ATP = adenosine triphosphate, $\mathrm{ADP}=$ adenosine diphosphate.)

The idea of ATP hydrolysis as the first energy-yielding reaction, supplying the contractile fibrils, thus arose, CP breakdown having the role of bringing about ATP resynthesis.

Further work on carbohydrate breakdown from the laboratories of Meyerhof and of Warburg showed that there are two markedly exothermic stages in the breakdown series between glycogen and lactic acid: dephosphorylation of phosphopyruvic acid and dephosphorylation of diphosphoglyceric acid. Experiments in extracts showed that these compounds cannot phosphorylate creatine, but do react with the adenylic compounds, e.g.:

Phosphopyruvic acid + ADP $\rightarrow$ pyruvic acid + ATP. (For literature, see Needham, 1937, 1941.)

Thus the energy to be obtained by breakdown both of creatine phosphate and of glycogen seems to be used to keep up the supply of ATP, the former being more important immediately after stimulation, the latter at later stages of contraction.

While thus placing ATP in the centre of the picture as the essential fuel, we must bear in mind that two important assumptions are made:

(I) That ATP is really dephosphorylated. Direct evidence for this in muscle is found only in severe fatigue. Experiments to settle this point for ordinary contraction by means of radioactive phosphorus are not simple to carry out since, as Kalckar (1944) has shown, the rate of exchange of the terminal phosphate group is high even in resting muscle.

(2) That the dephosphorylation goes on with production of free energy. So far only the heat of hydrolysis of ATP has been measured and not the free energy which is made available. Calculations indicating that the free energy is of the same order as the heat change involve a number of assumptions and approximations. 
This scheme outlined for the energy provision, derived partly from work on excised muscle, partly from work on extracts, fits in well with observations on the intact working animal, e.g. of the increased creatine and phosphate excretion and the rise in blood lactate. It is interesting that the rise in $\mathrm{pH}$ of the muscle itself early in exercise, to be expected from the relatively high initial CP breakdown, has been observed in human subjects.

But in the whole organism we have to consider mainly contraction in aerobic conditions-the conditions are partly anaerobic only at the beginning of exercise before the circulation is adjusted and in late stages when the heart fails to keep pace with demands. The old idea that lactic acid production is a constant accompaniment of contraction, whether anaerobic or aerobic, has had to be discarded, since observations on the whole animal and on human beings show that much work can go on without any indication of lactic acid formation-indeed, according to Margaria, Edwards \& Dill (1933) no extra lactic acid appears in the blood up to a rate of work corresponding to two-thirds of the maximum metabolic rate. After this the blood lactic acid does increase rapidly. They observed a rate of oxygen uptake during work some thirty times as great as the maximum in the period immediately after work. It seems that during work oxidations are going on which can supply energy directly for the resynthesis of ATP; carbohydrate is largely the substrate, as is indicated by the R.Q. often approximating to unity. Quite possibly the course of breakdown is the same as the anaerobic course as far as pyruvic acid; then the latter, instead of being reduced to lactic acid, is oxidized via the Krebs cycle. Experiments on tissue homogenates show that oxidation of pyruvate can lead to marked esterification of phosphate, about three atoms of phosphorus being esterified for each atom of oxygen used. The intermediate phosphorylated compounds capable of phosphorylating ADP have not yet been identified with certainty, but there is no doubt of the efficacy of carbohydrate oxidation in bringing about ATP synthesis. Indeed, per molecule of glucose, this oxidative phosphorylation is about ten times as effective as the phosphorylation connected with lactic acid formation.

\section{The muscle machine}

In turning now to the nature of the muscle machinery, we must look to the proteins. The modern phase of work on muscle proteins began with the study of myosin by Edsall (1930) and von Muralt \& Edsall (1930a,b). The double refraction of flow of solutions of this protein at once suggested a connexion with the anisotropic bands of the myofibrils. The facts that it is the only one of the muscle proteins which would be in the gel form under the conditions obtaining within the muscle and that it constitutes about $60 \%$ of the muscle protein extractable by salt solution, indicate that the myofibrils consist throughout their length of myosin. The difference between the anisotropic and the isotropic bands has been put down to difference in arrangement of the myosin molecules in the two parts. It seems that the other muscle proteins-the globulin X, myogen and myoalbumin fractions-are in solution and contained in the sarcoplasm which surrounds the bundles of myofibrils (Bate-Smith, 1933-4). A very large proportion, if not all, of these proteins must have enzymic properties. 
The indication from double-refraction studies that the myosin micelle is an asymmetric, long particle has been borne out by X-ray studies. Artificial myosin threads and muscle itself both give, in the unstretched state, the $\alpha$ diagram of a fibrous protein, whereas upon stretching the $\beta$ diagram is obtained. It seems that upon muscle contraction the myosin chains of the resting muscle undergo a further folding analogous to the supercontraction of keratin fibres. Thus the contractile fibrils would consist of polypeptide chains of myosin showing the $\alpha$ fold and owing their elasticity and longrange contractility to their power of straightening out to the fully extended chain or folding up still further.

We come now to the link between the machinery and the fuel in the discovery by Liubimova \& Engelhardt (1939) that ATPase activity seems to belong to the myosin. Machinery and fuel thus stand to one another in the relation of enzyme and substrate, and hypothesis as to the manner of transfer of free energy from the ATP to the myosin molecule becomes possible.

Szent-Györgyi and his collaborators (see Szent-Györgyi, 1947) recently found that the properties of myosin vary according to the length of time during which the muscle is subjected to extraction with salt solution. With longer treatment, a new protein (actin) can be extracted and this was purified. When myosin and actin are mixed in $0.5 \mathrm{M}-\mathrm{KCl}$, a great increase in viscosity and double refraction of flow takes place. Further, addition of ATP causes immediate fall in these values. The two proteins, myosin and actin, both themselves fibrous, unite to form fibrils of very much greater length, and this complex formation is reversed by addition of ATP. If now the ATP is added to actomyosin in very dilute potassium salt solution $(0.05 \mathrm{M})$ instead of splitting of the complex, precipitation of the actomyosin is obtained. The precipitation consists in shrinking, with great water loss, of the actomyosin gel. These results are reversible. Bailey \& Perry (1947) have since indicated very clearly that myosin and actin combine through the $\mathrm{SH}$ groups of the myosin and that ATP displaces actin by itself combining with the same SH groups. Muscle seems to contain about one-third as much actin as myosin, no doubt in the fibrils, but whether free or as actomyosin is not known.

\section{The phenomenon of fatigue}

In the light of the facts already assembled, we might consider the phenomenon of fatigue. It seems that fatigue is not due to the using up of the chemical sources of energy supply. A cause often suggested as important is the accumulation of harmful products such as lactic acid. The presence of such products, with consequent changes including those in $\mathrm{pH}$, may affect enzymes concerned in energy provision. Cori \& Green (1943) for example, have found the activity of phosphorylase preparations from fatigued muscle much below that of preparations from resting muscle. The change is due to reversible splitting off of a prosthetic group.

The structure of the contractile fibrils themselves may perhaps be affected by prolonged contraction. The partly folded polypeptide chains are held in place by intermolecular links of various types. Some of these must be broken and rearranged when the further folding of contraction takes place; if contraction is too severe and 
prolonged, too great distortion may perhaps take place, with unusual breaking of links or formation of new and inconvenient ones. That the myosin chains are affected is confirmed by the fact that fatigue leads to decreased solubility in salt solutions (Deuticke, 1932).

The leakage out of potassium ions, which accompanies contraction (apparently due to the setting free of potassium from some indiffusible combination), may also have important effects on enzyme activity and protein structure.

\section{Mechanism of contraction}

With regard to possible mechanisms of contraction, two most interesting questions at the present time are the exact parts played by actin and by ATP. Szent-Györgyi upholds the view that the contracting fibrils consist of actomyosin rather than myosin. As we have seen, if ATP comes into contact with actomyosin fibrils at certain low salt concentrations, there is a rapid change in the protein with great loss of water. SzentGyörgyi regards this process as in some degree synonymous with contraction, perhaps initiated by slight changes in potassium-ion concentration in the neighbourhood of the fibrils. Astbury (Astbury, 1947; Astbury \& Dickinson, 1940), on the other hand, has suggested that in the resting muscle the fibrils are made more rigid and stable by combination in parts with a parallel actin system, and that upon stimulation this combination is loosened by the action of ATP. When this happens the myosin can take up the shortened form of folding.

We have at present no means of deciding whether breakdown of ATP actually accompanies contraction or whether the free energy for contraction is provided from energy stored in the protein chains, the ATP breakdown serving to reconstitute the energy-poor relaxed chains. The consensus of opinion is in favour of the latter view, that ATP breakdown is the first of the recovery processes.

\section{REFERENCES}

Astbury, W. T. (1947). Proc. roy. Soc. B, 134, 303 .

Astbury, W. T. \& Dickinson, S. (1940). Proc. roy. Soc. B, 129, 307.

Bailey, K. \& Perry, S. V. (1947). Biochim. Biophys. Acta, I, 506.

Bate-Smith, E. C. (1933-4). Proc. roy. Soc. B, I14, 494.

Cori, G. T. \& Green, A. A. (1943). F. biol. Chem. 151, 3 r.

Deuticke, H. J. (1932). Z. Physiol. Chem. 210, 97.

Edsall, J. T. (1930). F. biol. Chem. 89, 289.

Fletchet, W. \& Hopkins, F. G. (1917). Proc. roy. Soc. B, 89, 444.

Kalckar, H. M. (1944). F. biol. Chem. 154, 275.

Lohmann, K. (1934). Biochem. Z. 271, 264.

Liubimova, N. M. \& Engelhardt, V. A. (1939). Biochimia, 4, 716.

Lundsgaard, E. (1930). Biochem. Z. $217,162$.

Margaria, R., Edwards, H. T. \& Dill, D. B. (1933). Amer. F. Physiol. 106, 689.

Meyerhof, O. (1930). Die chemische Vorgänge im Muskel, ist ed. Berlin: Julius Springer.

Muralt, A. von \& Edsall, J. T. (1930a). F. biol. Chem. 89, 315.

Muralt, A. von \& Edsall, J. T. (1930b). F. biol. Chem. 89, 35 I.

Needham, D. M. (1937). Article in Perspectives in Biochemistry, 1st ed. Cambridge: The University Press.

Needharn, D. M. (1941). Ann. Rep. chem. Soc. 38, 241 .

Szent-Györgyi, A. (1947). Chemistry of Muscular Contraction, ist ed. New York: Academic Press. 